\title{
IMPACT OF INTEGRATING SOLAR TECHNIQUE ON BUILDINGS'THERMAL COMFORT AND ENERGY CONSUMPTION: A NUMERICAL STUDY
}

\author{
Sahar Ben Romdhane ${ }^{1 *}$, Zohir Younsi ${ }^{2}$, Hassan Naji ${ }^{2}$, Nejla Mahjoub Said ${ }^{3,4}$, and Abdelmajid Jemni ${ }^{1}$ \\ ${ }^{1}$ LESTE, National Engineering School of Monastir, 5000 Monastir, University of Monastir, Tunisia \\ ${ }^{2}$ Univ. Artois, Univ. Lille, IMT Lille-Douai, Junia-HEI Hauts de France, Laboratoire Génie Civil \& géo-Environnement (ULR 4515), \\ Technoparc Futura, F-62400 Béthune, France. \\ ${ }^{3}$ Department of Physics, College of Science, King Khalid University, Abha, 61413, Saudi Arabia \\ ${ }^{4}$ LGM, Preparatory Institute for Engineering Studies, University of Monastir, Tunisia
}

\begin{abstract}
In the context of shrinking non-renewable energy resources and reducing greenhouse gas emissions, it turns out necessary to drop energy consumption and move towards renewable energy sources. In this regard, solar energy being an abundant source of energy, it can play an important role in the building energy supply. This energy supplement can come from passive solar technologies, of which the Trombe wall is one of the passive models most used in the building envelope, whose main role is to ensure net gains. Thereby, the main aim of this study is to highlight the use of a simple method to reduce the buildings heating demand. For this, a 3-D model was developed through scSTREAM V2020 software to investigate the thermal performance of a classical Trombe wall in winter while targeting desirable indoor thermal comfort conditions. In addition, studies have been performed to optimize the energy consumption It turned out that, in the presence (respectively absence) of solar irradiation, the Trombe wall acts as a solar absorber (respectively a heat source).
\end{abstract}

\section{Nomenclature}

$\rho$ is the density $\left(\mathrm{kg} / \mathrm{m}^{2}\right), \mathrm{k}$ is the thermal conductivity (W/m.K), $\mu$ is the dynamic viscosity (Pa.s), $\mathrm{u}$ is the velocity $(\mathrm{m} / \mathrm{s}), \mathrm{p}$ is the static pressure $(\mathrm{Pa}), \mathrm{T}$ is the temperature $(\mathrm{K}), \vec{F}$ is the external body force $\left(\mathrm{N} / \mathrm{m}^{2}\right)$ and $\mathrm{S}_{\mathrm{h}}$ is the volumetric energy source.

\section{Introduction}

Solar architecture using solar energy has started to regain popularity due to its ability to meet global demand and provide a solution in terms of energy saving and today. In addition, it is worth noting that there has since been a noteworthy promotion of renewable solar energy. Several researches are carried out to exploit the power of solar energy via many technologies from the method of conventional constructions to new designs to conceive bioclimatic and / or zero energy buildings [1, 2]. One of the most widely used solar technologies is that using a passive Trombe wall, also called a solar wall $[3,4]$. It is a high thermal mass concrete wall designed to passively store solar energy in a building $[5,6]$. An experimental study was set up by Rabani et al. [7,8] to investigate the heating performance of an improved Trombe wall that is able to obtain solar radiation from three directions: sou th, west and east. Besides, they performed numerical simulations and validated their findings with the experimental data then compared the heating performances of two test rooms: one with a new newly designed Trombe wall, while the second with a traditional Trombe wall. It should also be noted that intense efforts are underway to implement solutions for the renovation of inefficient existing buildings by a group of Spanish scientists [9] to attempt mitigating greenhouse gas emissions related to their consumption of energy. To deal with this problem, one of the possibilities is to integrate thermal insulation materials. Mohamad et al. [10] even proposed a new design consisting of heating and ventilating rooms using solar energy during the winter season. Such a design can reduce the cooling load during the summer season. The modified Trombe wall including a water tank was found to be more thermally efficient and lighter while providing a faster response for charging and discharging processes compared to conventional Trombe walls. Hashemi et al. [11] pointed out the Trombe wall temperature variation effect. Thereby, this parameter has been studied by taking into account the air flow velocity, the average air temperature, the solar radiation and the channel dimensions. They indicated that solar radiation is the most influential parameter that affects temperature variation. Recently, Dabaieh et al. [12] conducted a study of a passive house for refugees in a Swedish climate. Such a house includes an air heat exchanger, a Trombe wall and a green wall. With this innovative design, they have succeeded in reducing cooling and heating loads while saving primary energy and mitigating emissions. In addition, the use of

\footnotetext{
*Corresponding author: br.sahaar@gmail.com
} 
renewable sources allowed to produce an annual surplus of $180 \mathrm{kWh} / \mathrm{m}^{2} /$ year. As a result, a prototype has been implemented in Lund, Sweden to verify the performance of the three passive systems for one year.

The aim targeted here is to provide a comparative study of two configurations, i.e. a Trombe Wall with and without insulation. The comparisons were achieved using scSTREAM V2020 showing the dynamic and thermal fields. The results, thereby, obtained demonstrate the use effectiveness of an insulator for a passive solar system which allows the activation of thermal comfort.

\section{Analysis and modelling}

\subsection{Test room description}

The physical model studied including two south-facing Trombe walls is a room whose dimensions are $6.7 \mathrm{~m} \times$ $10.91 \mathrm{~m} \times 2.67$ (Fig. 1). The Trombe wall 1 measures $1.55 \mathrm{~m} \times 2.67 \mathrm{~m}$, while the Trombe wall 2 is $2.7 \mathrm{~m} \times$ $2.67 \mathrm{~m}$.

The storage material is concrete $0.25 \mathrm{~m}$ thick with an absorbance of 0.95 . The air gap thickness between the massive walls and the glazed surface is $0.3 \mathrm{~m}$. A total of twelve vents with the same size connect the Trombe walls with the test room. Their size is $0.4 \mathrm{~m} \times 0.2 \mathrm{~m}$. The test room has also two widows and two doors.

It should be noted that this study covers the following two configurations:

- Configuration 1 with the uninsulated Trombe wall.

- Configuration 2 with the insulated Trombe wall.

\subsection{Boundary conditions}

To simplify the model, the following assumptions, initial conditions and limits are adapted to all the cases deemed herein:

- The fluid (air) is considered incompressible.

- The analysis is transient with the same starting time, namely 7 am to $12 \mathrm{pm}$.

- Solar radiation is modeled via software solar ray tracing.

- Viscous stress is ignored.

- The buoyancy force is translated using the Boussinesq approximation.

- A convection boundary condition is regarded for the glazed parts and the wooden door.

- The thermal convection coefficient is approximately $7.69 \mathrm{~W} / \mathrm{m}^{2} . \mathrm{K}$.

- The external radiation temperature is equal to the ambient temperature.

- All walls except Trombe walls, glazing and doors are assumed adiabatic.

\subsection{Governing equations}

Based on the up-mentioned assumptions, the governing Navier-Stockes equations (1-3) read:
- Continuity equation:

$$
\nabla \cdot(\rho \vec{u})=0
$$

- Momentum equation:

$$
\nabla \cdot(\rho \vec{u} \vec{u})=-\nabla \mathrm{p}+\nabla \cdot[\mu(\nabla \vec{u}+\nabla \vec{u})]+\vec{F}
$$

- Energy equation:

$$
\nabla \cdot(\vec{u}(\rho T))=\nabla \cdot(k \nabla \mathrm{T})+S_{h}
$$

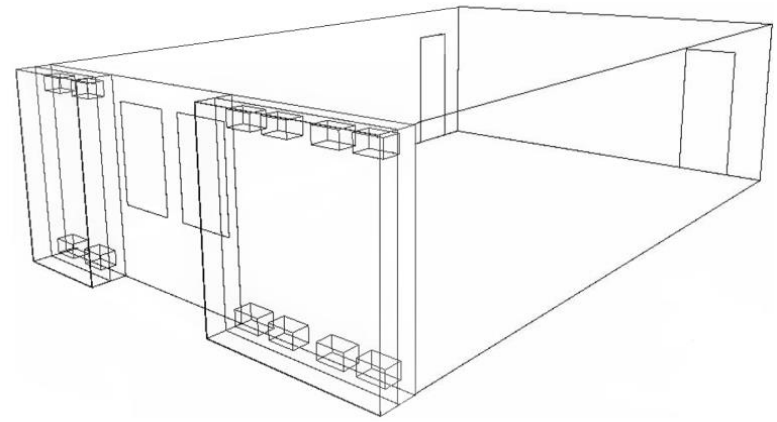

Fig. 1. Illustrative diagram of the test room

\section{Software validation}

Based on the literature [7, 8], a CFD model was considered to validate the scSTREAM V2020 software before proceeding with the targeted simulations.

A structured mesh was generated via scSTREAM V2020 and a series of tests with a time step ( $\Delta \tau=1 \mathrm{~s}$ and $\Delta \tau=0.5 \mathrm{~s}$ ) was carried out for two different grids, namely 14580 elements and $10^{6}$ elements.

Fig. 2(a) and 2(b) show the temporal evolution of the temperature. It appears that it is the second mesh $\left(10^{6}\right.$ elements) associated with the time step of $0.5 \mathrm{~s}$, which gives satisfactory results.

Thereby, the subsequent simulations are based on these parameters having validated the code.

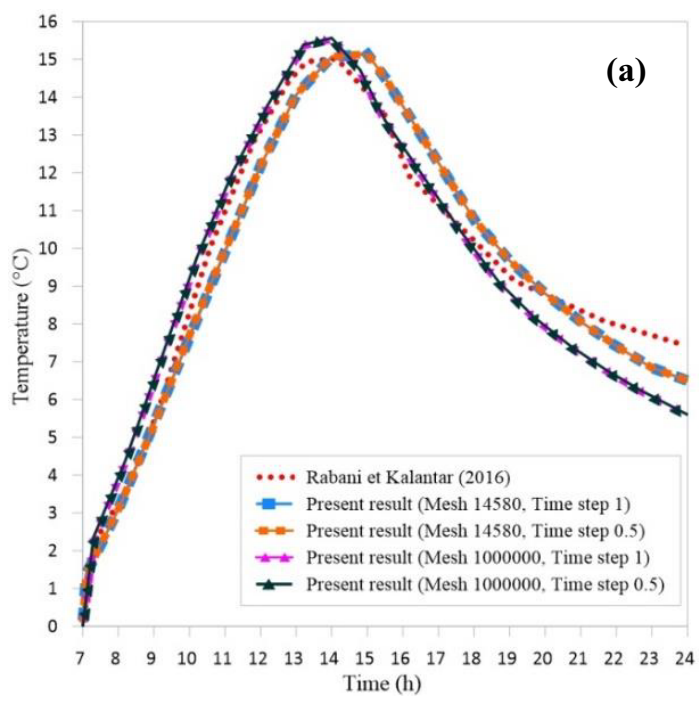




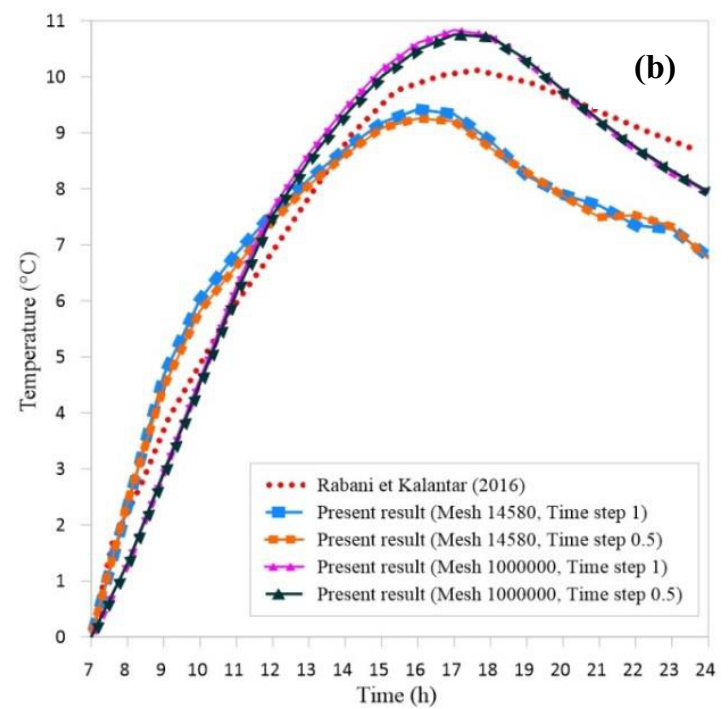

Fig. 2. Comparison between simulation results and experimental data for the Normal Trombe wall for different mesh sizes (a) absorber, (b) back of the Trombe wall.

\section{Results and discussion}

Before presenting and commenting on the results of the simulation, it is advisable to point out the simulation conditions: it was implemented during a typical winter morning with an outside air temperature of $-1{ }^{\circ} \mathrm{C}$. In addition, the initial indoor temperature is set at $16^{\circ} \mathrm{C}$ and solar radiation is taken into account via the relationship implemented in the scSTREAM V2020 code.

Fig. 3 depicts temporal evolutions of temperature of the two absorbers.

After direct sunlight passes through the glass, the temperature of the glass and the trapped air begins to rise. As a result, a buoyancy effect occurs, as can be seen in Fig. 4, thereby driving the air from the bottom to the top of the channel.

Moreover, at the day start, the temperature behind the Trombe walls, in particular for configuration 1, drops until the solar energy absorbed by the absorbers spreads through the walls.

The transfer of the heat collected by thermocirculation from the air gap to the interior of the test room occurs through the vents. Afterward, the heated air enters the room through the upper vents and cools down when it comes into contact with the walls of the room, and then returns through the lower vents.

At sunrise, the absorbers temperature for both cases is closer to each other. After that, the temperature of configuration 1 (Trombe wall without insulation) reaches its maximum $\left(32{ }^{\circ} \mathrm{C}\right)$ for both absorbers, while for configuration 2 (Trombe wall with insulation), it continues to increase until reaching a maximum value of about $34{ }^{\circ} \mathrm{C}$. Note that this maximum is reached at 2:00 p.m. in both cases. The slight difference between the Absorber 1 and the Absorber 2 is $0.3{ }^{\circ} \mathrm{C}$. This difference is due to the direction of the solar radiation.

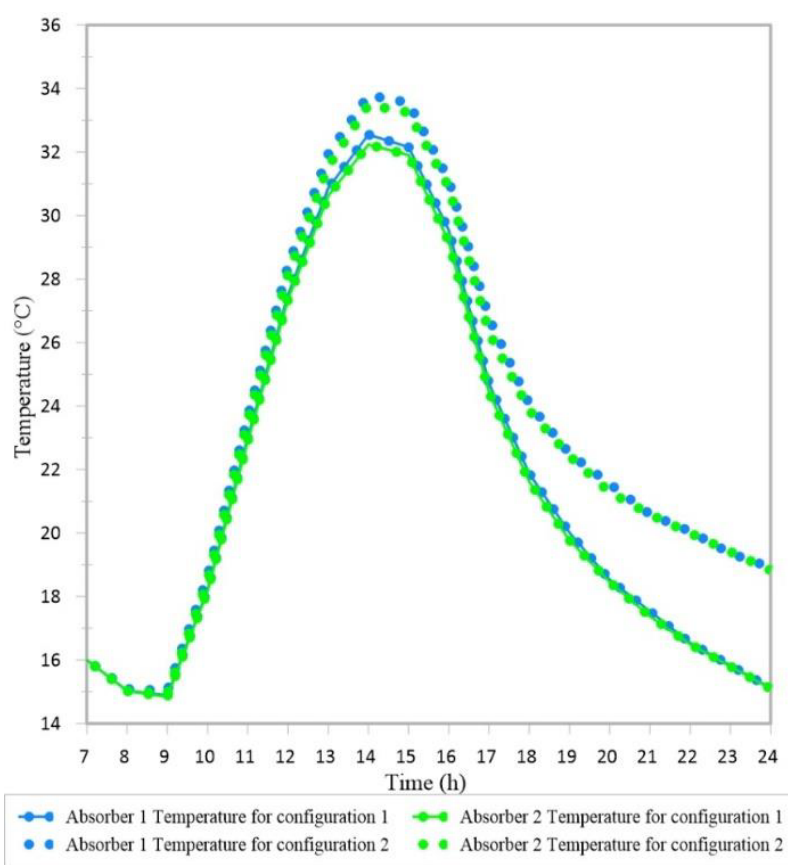

Fig. 3. Evolution of the absorbers temperature.

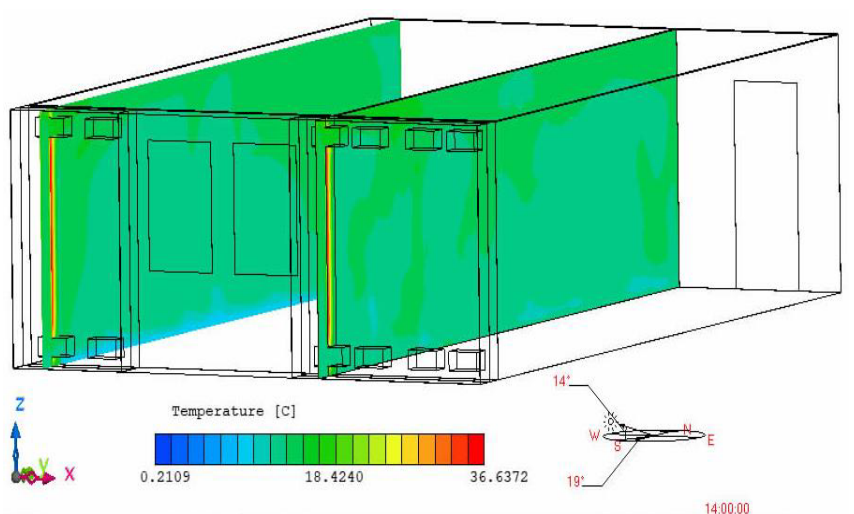

Fig. 4. Temperature distribution at 14:00 for configuration 1 .

Fig. 5 depicts the temperature evolution at the back of the Trombe walls. It can be observed that, in the case of configuration 1 , the heat reaches the back of the wall of the case of configuration 1 before compared to the case of configuration 2 .

Note that the analysis of Fig. 3 and Fig. 5 allows to state that the temperature of the absorbers is higher than that of the rear of the Trombe walls due to the loss of energy which was transferred by conduction of the absorbers to the rear of the Trombe walls. 


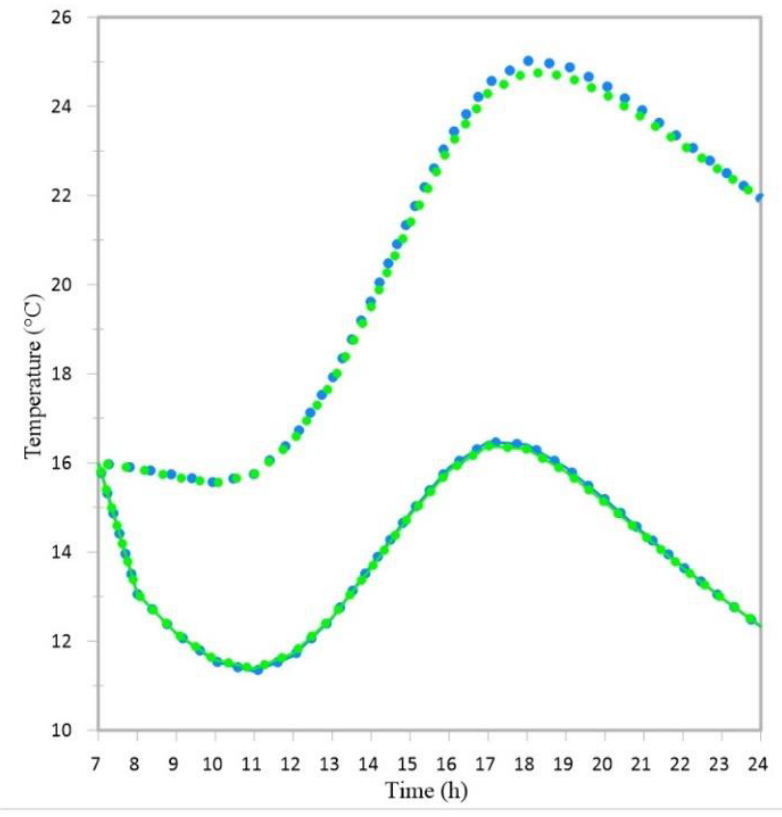

$\rightarrow$ Back of the Trombe wall 1 Temperature for configuration $1 \leftrightarrow$ Back of the Trombe wall 2 Temperature for configuration 1

- Back of the Trombe wall 1 Temperature for configuration 2 - Back of the Trombe wall 2 Temperature for configuration 2

Fig. 5. Evolution of the Back of the Trombe walls Temperature for the two configurations.

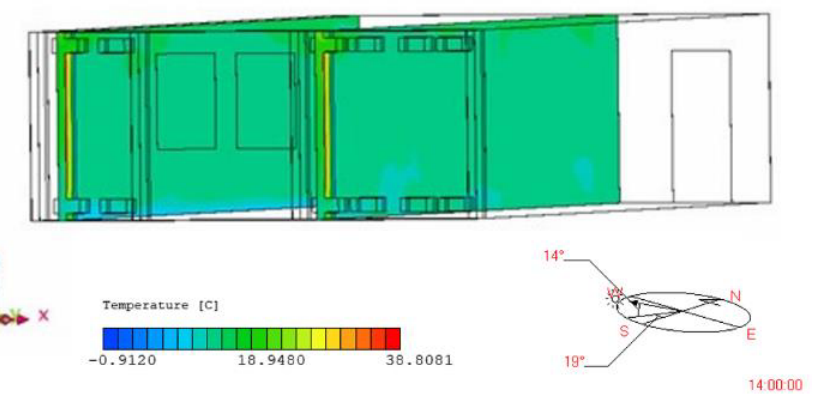

Fig. 6. Temperature distribution at 14:00 for configuration 2 .

According to Fig. 6, the Trombe insulation wall (configuration 2) appears to have the ability to further improve heat absorption during the heating season, as the sun's rays directly strike its surface. It collects energy during the day and then releases it at night. It is also noted that the temperature variations are sensitive to the evolution of solar radiation. Its increase or decrease depends on that of solar radiation flux.

As illustrated in Fig. 7 and Fig. 8, the air velocity is concentrated on the upper vent of the Trombe walls, with an average velocity of $0.1 \mathrm{~m} / \mathrm{s}$ and a maximum of approximately

$0.27 \mathrm{~m} / \mathrm{s}$.

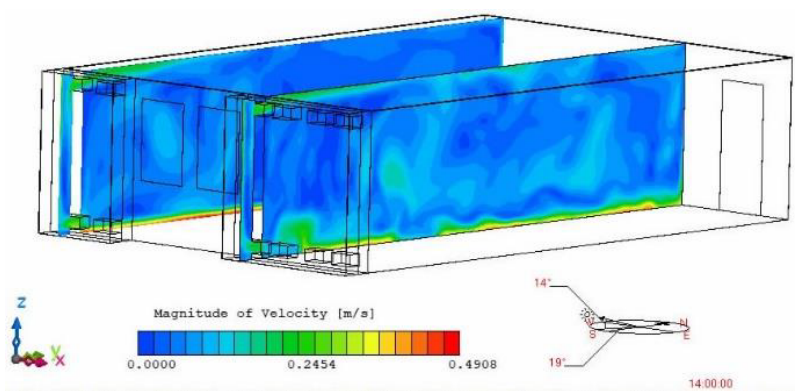

Fig. 7. Velocity distribution at 14:00 for configuration 1.

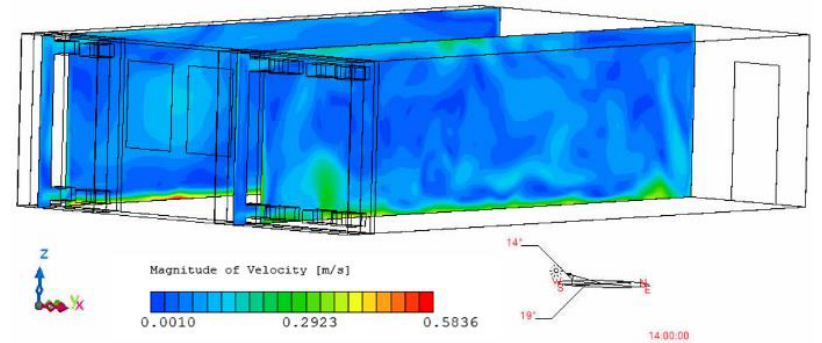

Fig. 8. Velocity distribution at 14:00 for configuration 2 .

This is within the required air speed range, which meets the criteria for indoor comfort conditions [13]. An average velocity of $0.28 \mathrm{~m} / \mathrm{s}$ for the top vents of Trombe 1 wall (Fig. 8) and $0.3 \mathrm{~m} / \mathrm{s}$ for the top vents of Trombe 2 wall of configuration 2 (Fig. 8) is shown compared to that of $0.25 \mathrm{~m} / \mathrm{s}$ for the Trombe 1 wall and $0.27 \mathrm{~m} / \mathrm{s}$ for the Trombe 2 wall for configuration 1 (Fig. 7).

\section{Conclusions}

This study dealt with on the numerical investigation of a Trombe wall to mitigate buildings' heating demand. Numerical simulation allowed obtaining and comparing the temperature and velocity distributions at the Trombe walls. Simulation findings revealed that the Trombe wall can be considered as an effective passive ventilation technique during winter season. However, when integrating the Trombe walls into the building envelopes, there are some influential elements to be considered, such as the design parameters, namely the glazing properties, Trombe wall surface kind, the canal depth, etc.

Finally, it should be pointed out that the site parameters certainly have a great influence on the wall Trombe performance (sun radiation and orientation, velocity and direction of the wind). In addition, the interior temperature can be further improved by the insulated Trombe wall. 


\section{References}

1. Z. Tian, X. Zhang, X. Jin, X. Zhou, B. Si, X. Shi, Energy Build. 158,1306-1316 (2018).

2. X. Sun, Z. Gou, S.S.Y. Lau, J. Clean. Prod. 183, 3545 (2018).

3. X. Fang, T. Yang, Appl. Therm. Eng. 28, 22892294 (2008).

4. K. Hami, B. Draoui, O. Hami, Energy. 39, 11-16 (2012).

5. Z. Hu, W. He, J. Ji, S. Zhang, Renew Sustain Energy Rev. 70, 976-987 (2017).

6. S. B. Sadineni, S. Madala, R.F. Boehm, Renew Sustain Energy Rev. 15, 3617-3631 (2011).

7. M. Rabani, V. Kalantar, Heat Mass Transfer. 52, 1139-1151 (2016).

8. M. Rabani, V. Kalantar, A.A. Dehghan, A.K. Faghih, J. Sol. Energy. 118, 359-374 (2015).

9. F. Martín-Consuegra, C. Alonso, G. Pérez, B. Frutos, A. Guerrero, I. Oteiza, ABER. 1756-2201 (2019).

10. Mohamad, J. Taler, P. Ocloń, Energies 12, 285 (2019).

11. S.H. Hashemi, M. Dinmohammad, S.A. Hashemi, MESE. 6, 2655-2659 (2020).

12. M. Dabaieh, A.A. Serageldin. Energy Convers Manag. 209, 112555 (2020).

13. ANSI/ASHRAE Standard 55-2004. Thermal Environmental Conditions for Human Occupancy, American Society of Heating, Refrigerating and Air-Conditioning Engineers, Inc. Atlanta, GA. 